\title{
Destruction of Trace Organics in Otherwise Ultra Pure Water
}

\author{
M.R. Prairie, B.M. Stange, S.K. Showalter, and K.A. Magrini
}

\section{Prepared by}

Sandia National Laboratories

Albuquerque, New Mexico 87185 and Livermore, California 94550 for the United States Department of Energy under Contract DE-AC04-94AL85000

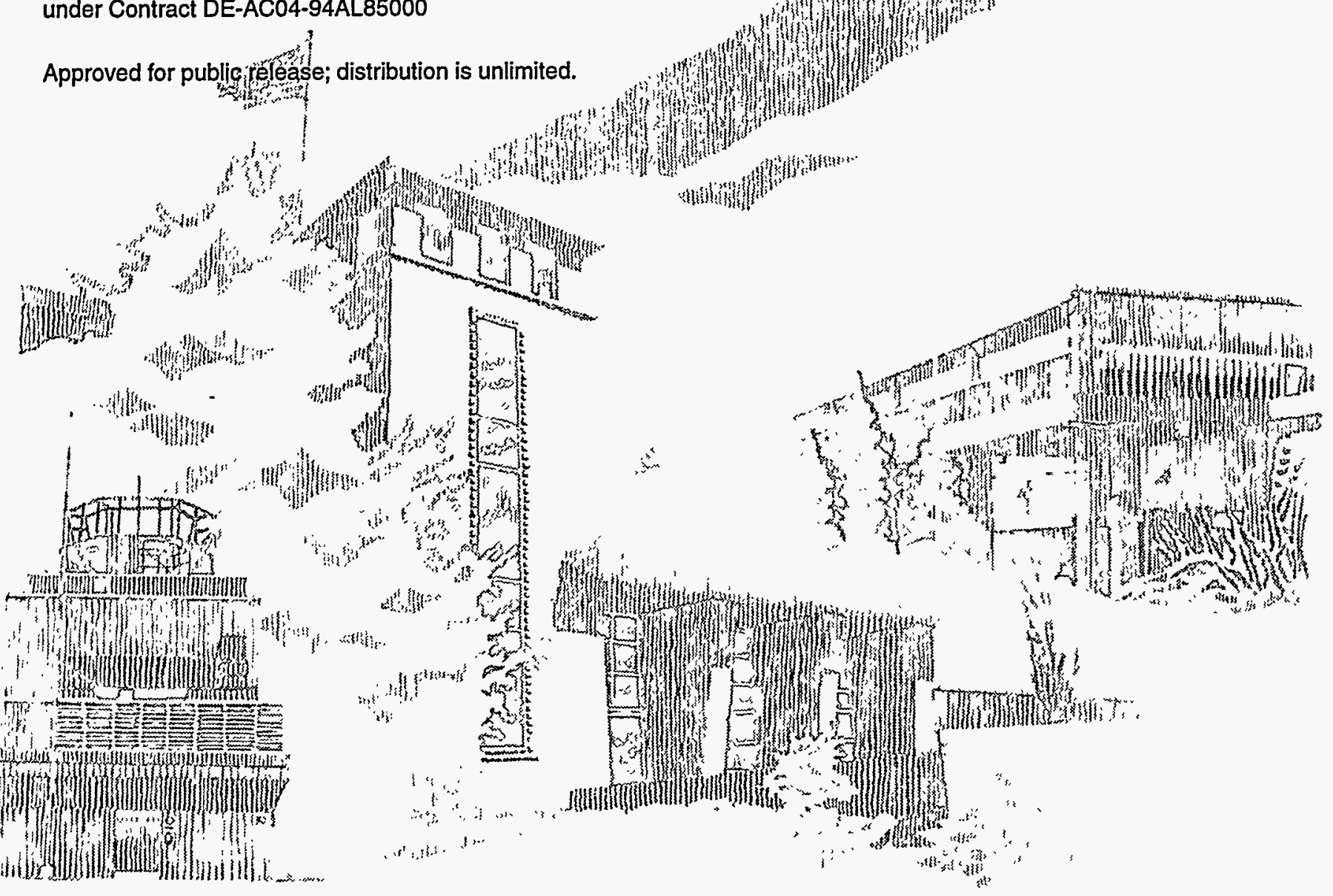




\begin{abstract}
Issued by Sandia National Laboratories, operated for the United States Department of Energy by Sandia Corporation.

NOTICE: This report was prepared as an account of work sponsored by an agency of the United States Government. Neither the United States Government nor any agency thereof, nor any of their employees, nor any of their contractors, subcontractors, or their employees, makes any warranty, express or implied, or assumes any legal tiability or responsibility for the accuracy, completeness, or usefulness of any information, apparatus, product, or process disclosed, or represents that its use would not infringe privately owned rights. Reference herein to any specific commercial product, process, or service by trade name, trademark, manufacturer, or otherwise, does not necessarily constitute or imply its endorsement, recommendation, or favoring by the United States Government, any agency thereof or any of their contractors or subcontractors. The views and opinions expressed herein do not necessarily state or reflect those of the United States Government, any agency thereof or any of their contractors.
\end{abstract}

Printed in the United States of America. This report has been reproduced directly from the best available copy.

Available to DOE and DOE contractors from

Office of Scientific and Technical Information

PO Box 62

Oak Ridge, TN 37831

Prices available from (615) 576-8401, FTS 626-8401

Available to the public from

National Technical Information Service

US Department of Commerce

5285 Port Royal Rd

Springfield, VA 22161

NTIS price codes

Printed copy: A02

Microfiche copy: A01

\title{
DISCLAIMER
}

This report was prepared as an account of work sponsored by an agency of the United States Government. Neither the United States Government nor any agency thereof, nor any of their employees, makes any warranty, express or implied, or assumes any legal liability or responsibility for the accuracy, completeness, or usefulness of any information, apparatus, product, or process disclosed, or represents that its use would not infringe privately owned rights. Reference herein to any specific commercial product, process, or service by trade name, trademark, manufacturer, or otherwise does not necessarily constitute or imply its endorsement, recommendation, or favoring by the United States Government or any agency thereof. The views and opinions of authors expressed herein do not necessarily state or reflect those of the United States Government or any agency thereof. 
SAND94-3170

Distribution

Unlimited Release

UC-1303

Printed December 1995

\title{
Destruction of Trace Organics in Otherwise Ultra Pure Water
}

\author{
M.R. Prairie, B.M. Stange, and S.K. Showalter \\ Solar Thermal Technology Department \\ Sandia National Laboratories \\ Albuquerque, NM 87185-0703 \\ K.A. Magrini \\ National Renewable Energy Laboratory \\ 1617 Cole Blvd \\ Golden, CO 80401
}

\begin{abstract}
A number of experiments were conducted to determine the economic viability of applying various ultraviolet (UV) oxidation processes to a waste water stream containing approximately $12 \mathrm{mg} / \mathrm{L}$ total organic carbon (TOC), predominately ethylene glycol. In all experiments, a test solution was illuminated with either near-UV or a far-UV light alone or in combination with a variety of photocatalysts and oxidants. Based upon the outcomes of this project, both UV/photocatalysis and UV/ozone processes are capable of treating the water sample to below detection capabilities of TOC. However, the processes are fairly energy intensive; the most efficient case tested required $11 \mathrm{kWh}$ per order of magnitude reduction in TOC per $1000 \mathrm{~L}$. If energy consumption rates of 5-10 $\mathrm{kWh} / 1000 \mathrm{~L}$ are deemed reasonable, then further investigation is recommended.
\end{abstract}

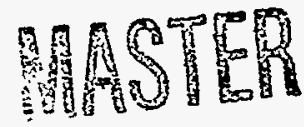




\section{Acknowledgment}

This project was funded by Intel Corporation under a Cooperative Research and Development Agreement (CRADA No. SC93/01154) between Intel and Sandia; work at NREL was funded by DOE/EE222.

The authors thank Ed Wolfrum of NREL for the loan of the photoreactor used at Sandia for experiments described herein, and for his valuable advice. We also thank Gregg Carr and Scott Sibbett of Intel, Reinhard Hanselka of Advanced Intelligent Designs, Inc., and Art Verado of Sandia for their contributions to this project. 


\section{Contents}

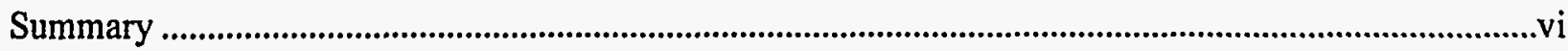

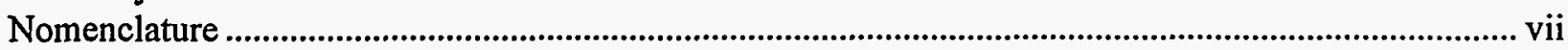

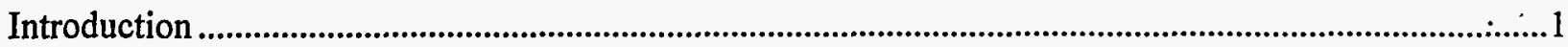

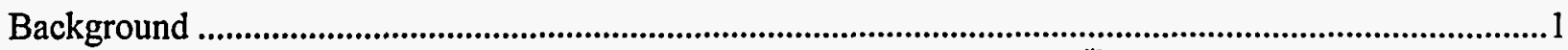

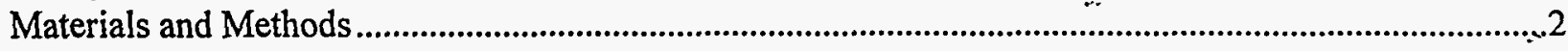

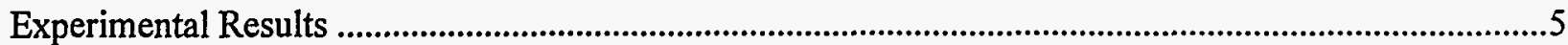

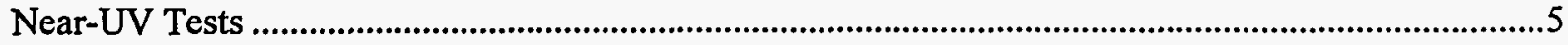

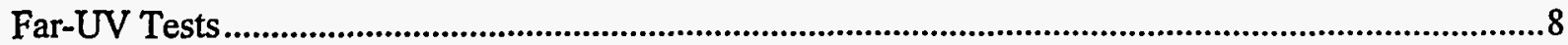

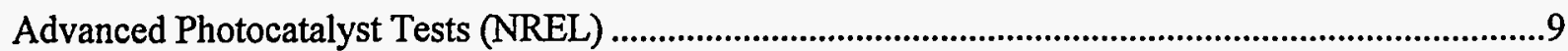

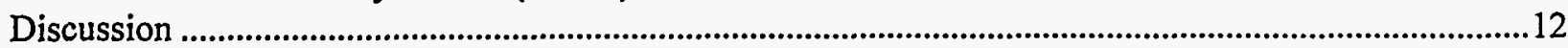

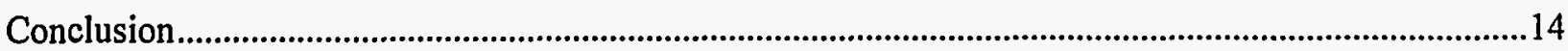

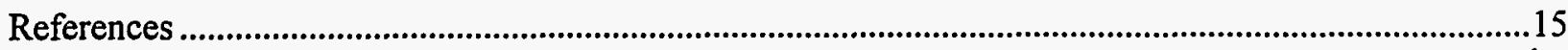

\section{Figures}

1 Photograph and flow schematic of the bench scale recirculating photoreactor.........................................

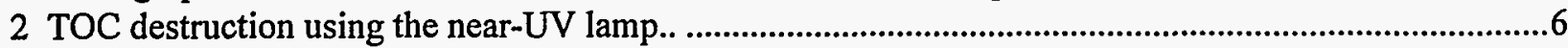

3 The effects of hydrogen peroxide on the photocatalytic degradation of TOC.........................................7

4 Sodium persulfate inhibits the photocatalytic degradation of TOC............................................................7

5 TOC destruction using the far-UV lamp; photocatalytic comparisons..................................................8

6 TOC destruction with the far-UV lamp and hydrogen peroxide..............................................................9

7 Photocatalyst activity for ethylene glycol destruction using four different catalysts. ..................10

$8 \mathrm{Au}-\mathrm{Pt} / \mathrm{TiO}_{2}$ (Aldrich) versus Degussa $\mathrm{P}_{25} \mathrm{TiO}_{2}$ base case..................................................................10

9 Photocatalyst activity for ethylene glycol destruction using four different catalysts ...................11

\section{Tables}

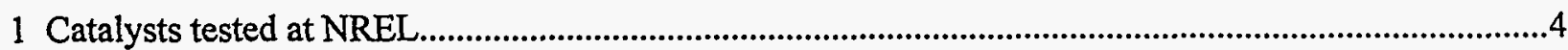

2 Relative catalyst activities for aqueous ethylene glycol oxidation.............................................12

3 Summary of energy and oxidant requirements for the seven most interesting cases. ...........................13 


\section{Summary}

This report details experiments that were performed to determine the economic viability of various ultraviolet (UV) advanced oxidation processes for destroying total organic carbon (TOC) in a specific waste stream at Intel Corporation (Intel). The waste water sample that was provided by Intel for evaluation at Sandia contained approximately 12 $\mathrm{mg} / \mathrm{L} \mathrm{TOC}$, predominately ethylene glycol. A second sample containing $19 \mathrm{mg} / \mathrm{L}$ of ethylene glycol in ultra pure water was used for supplemental studies that were conducted at the National Renewable Energy Laboratory (NREL). In all experiments, either a nearUV $(365 \mathrm{~nm})$ or a far-UV $(200 \mathrm{~nm})$ light source was used in a sealed, batch recirculation photoreactor alone or in combination with a variety of oxidants $\left(\mathrm{H}_{2} \mathrm{O}_{2}\right.$, persulfate, and ozone) and photocatalysts, including the commercially available Degussa $\mathrm{TiO}_{2}(\mathrm{P} 25)$ and several $\mathrm{TiO}_{2}$-based advanced formulations. The data that resulted were extrapolated to provide reasonable estimates of operating costs due to electrical and chemical consumption for achieving specified treatment goals. The most economical process studied consumed $10.6 \mathrm{kWh}$ electricity to destroy $90 \%$ of the TOC in 1000L of Intel water in under one hour at a cost of approximately $\$ 1$ (assuming an electricity cost of $\$ 0.10 / \mathrm{kWh}$ ). This near-UV process used a metallized photocatalyst derived from Aldrich $\mathrm{TiO}_{2}\left(0.5 \mathrm{wt} \% \mathrm{Au}+0.5 \mathrm{wt} \% \mathrm{Pt}\right.$ on $\left.\mathrm{TiO}_{2}\right)$, which was observed to be 3.7 times faster than P25. The best far-UV (uncatalyzed) process utilized $19 \mathrm{mg} / \mathrm{L} \mathrm{H}_{2} \mathrm{O}_{2}$.at the start of the reaction to yield a $90 \%$ reduction of TOC in approximately one hour, with $21 \mathrm{kWh}$ electricity consumed per $1000 \mathrm{~L}$ water. These results suggest that a small development effort with advanced catalysts and more efficient UV sources could produce a costeffective photocatalytic method for treating Intel waste water. 


\section{Nomenclature}

\begin{tabular}{|c|c|}
\hline $\begin{array}{l}\text { AOPs } \\
\text { TOC } \\
\text { UV } \\
\text { far-UV } \\
\text { near-UV }\end{array}$ & $\begin{array}{l}\text { advanced oxidation processes } \\
\text { total organic carbon } \\
\text { ultraviolet } \\
(\lambda<300 \mathrm{~nm}) \\
(\lambda>300 \mathrm{~nm} ; \lambda<400 \mathrm{~nm})\end{array}$ \\
\hline NREL & National Renewable Energy Laboratory \\
\hline $\begin{array}{l}\mathrm{kWh} \\
\mathrm{M}\end{array}$ & $\begin{array}{l}\text { kilowatt hour } \\
\text { mole/L }\end{array}$ \\
\hline $\begin{array}{l}\mathrm{Au} \\
\mathrm{CO}_{2} \\
\mathrm{Fe} \\
\mathrm{HCl} \\
\mathrm{HF} \\
\mathrm{H}_{2} \mathrm{O} \\
\mathrm{H}_{2} \mathrm{O}_{2} \\
\mathrm{Na}_{2} \mathrm{~S}_{3} \mathrm{O}_{8} \\
\mathrm{Ozone} \\
\mathrm{P} 25 \\
\mathrm{Pt} \\
\mathrm{SiO}_{2} \\
\mathrm{TiO}_{2}\end{array}$ & $\begin{array}{l}\text { gold } \\
\text { carbon dioxide } \\
\text { iron } \\
\text { hydrochloric acid } \\
\text { hydrofluoric acid } \\
\text { water } \\
\text { hydrogen peroxide; an oxidant } \\
\text { sodium persulfate; an oxidant } \\
\mathrm{O}_{3} \text {; an unstable, allotropic form of oxygen; an oxidant } \\
\text { Degussa } \mathrm{P} 25 \mathrm{TiO}_{2} \text {, a commercial photocatalyst } \\
\text { platinum } \\
\text { silica } \\
\text { titanium dioxide }\end{array}$ \\
\hline $\begin{array}{l}\mathrm{GC} \\
\text { ferrioxalate actinometry }\end{array}$ & $\begin{array}{l}\text { gas chromatograph } \\
\text { a chemical method for quantifying incident-light energy }\end{array}$ \\
\hline $\begin{array}{l}C \\
k \\
K \\
t \\
V \\
\text { gpm }\end{array}$ & $\begin{array}{l}\text { contaminant concentration } \\
\text { rate parameter }(\mathrm{mg} / \mathrm{L} / \mathrm{min}) \\
\text { rate parameter }(\mathrm{mg} / \mathrm{L} / \mathrm{min}) \\
\text { exposure time }(\mathrm{min}) \\
\text { reactor volume }(\mathrm{L}) \\
\text { gallon per minute }\end{array}$ \\
\hline$\lambda$ & $\begin{array}{l}\text { wavelength } \\
\text { variance }\end{array}$ \\
\hline
\end{tabular}




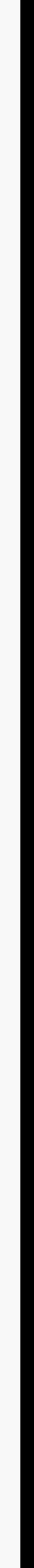




\section{Destruction of Trace Organics in Otherwise Ultra Pure Water}

\section{Introduction}

At the request of Intel Corporation (Intel), a number of experiments were conducted to determine the economic viability of applying various ultraviolet (UV) advanced oxidation processes (AOPs) to a specific waste water stream for the purpose of destroying total organic carbon (TOC). This is desirable because low-level concentrations of organics will interfere the reverse osmosis unit that would receive Intel waste water for recycling.

In all experiments, either a near-UV or far-UV light source was used in a batch recirculation photoreactor alone or in combination with a variety of photocatalysts and/or oxidants. The extrapolation of resulting data can provide a reasonable estimate of operating costs for achieving specified treatment goals.

This report describes the AOPs that were studied and evaluated to determine the economic feasibility of rendering Intel water recyclable using these methods. It also describes work performed at the National Renewable Energy Laboratory (NREL) to evaluate various photocatalysts for destruction of ethylene glycol, the primary contaminant in the Intel water sample.

\section{Background}

Mineralization is usually a goal for the treatment of waste water contaminated with low concentrations of organics; this refers to the complete conversion of organic species to inorganic species such as $\mathrm{CO}_{2}, \mathrm{H}_{2} \mathrm{O}$, and $\mathrm{HCl}$. Mineralization assures that a given (hazardous) organic is not simply converted to another (sometimes more hazardous) organic by-product. For most organics, oxidative processes are required to achieve mineralization. Indeed, the commercialization of AOPs for this purpose is occurring rapidly. Hydroxyl radicals are the reactive component in these processes; these radicals are powerful, indiscriminate oxidizing agents. In commercial applications, the most common AOPs utilize UV light combined with ozone (far-UV/ozone), hydrogen peroxide (far- $-\mathrm{UV} / \mathrm{H}_{2} \mathrm{O}_{2}$ ), or a photocatalyst (near-UV/TiO ${ }_{2}$ ) to generate hydroxyl radicals. Any combination of the three is possible, though one or the other is usually more effective depending on the target contaminant. For scale-up and determination of treatability, each of the processes require bench-top feasibility tests on the waste stream of interest. In dealing with low concentrations of organics, aggresive strategies are often required.

Titanium dioxide $\left(\mathrm{TiO}_{2}\right)$ is the most commonly used photocatalyst in commercial solar- and lamp-based detoxification systems. NREL is in the process of developing heterogeneous photocatalysts that can outperform standard $\mathrm{TiO}_{2}$ for commercial application. Chemical modification of the $\mathrm{TiO}_{2}$ surface by adding low loadings of platinum (Pt), gold (Au), and iron (Fe) can in certain situations increase reaction rate by as much as a factor of six. Studies have shown that metallizing $\mathrm{TiO}_{2}$ with gold increases hydrogen production from aqueous solutions of 
ethylene glycol [1], and platinizing $\mathrm{TiO}_{2}$ improves activity for a variety of reactions, including hydrogen production from aliphatic alcohols and the splitting of water [2]. This suggests that the addition of noble metals can facilitate reduction chemistry, which is thought to be rate-limiting for the destruction of organics by oxidation. Silica $\left(\mathrm{SiO}_{2}\right)$ and $\mathrm{Fe}$ have also been found to enhance the absorptive properties of $\mathrm{TiO}_{2}$.

Based upon these studies, three types of pure commercial $\mathrm{TiO}_{2}$ and a number of advanced catalysts were chosen for evaluation: Degussa $\mathrm{TiO}_{2}$, Aldrich $\mathrm{TiO}_{2}$, Hombicat $\mathrm{TiO}_{2}, \mathrm{Fe} / \mathrm{TiO}_{2}$ (Aldrich), $\mathrm{Au} / \mathrm{TiO}_{2}$ (Aldrich), $\mathrm{SiO}_{2} / \mathrm{TiO}_{2}$ (Degussa), and $\mathrm{Au}-\mathrm{Pt} / \mathrm{TiO}{ }_{2}$ (Aldrich).

\section{Materials and Methods}

This report details two sets of experiments that were performed at Sandia and at NREL. Sandia's work was directed at determining the treatability of a waste water sample, while the experiments at NREL focused on evaluating newly developed photocatalysts.

\section{Photoreactor}

All tests were performed in an annular batch recirculation photoreactor with an illuminated area of about $310 \mathrm{~cm}^{2}$. Reactor materials consist of Pyrex, Teflon, quartz, and stainless-steel parts that are impervious to most organic solutions. Specifically, the reactor consists of an inner quartz tube (27 mm OD) located concentrically within an outer Pyrex tube (35.5 mm ID). Teflon endcaps hold the tubes in place and provide fittings that allow flow in the annular space between the tubes and provide connections to the external flow loop. A UV lamp (44 cm long) inside the quartz tube irradiates the reactor solution. The illuminated portion of the photoreactor between the endcaps is $33 \mathrm{~cm}$ long.

\section{Flow Loop}

The flow loop consists of a $1 / 15$-hp centrifugal pump; the reactor; Teflon tubing, and a $1.5 \mathrm{~L}$ spherical jacketed vessel. Cooling water is pumped through the jacket to remove heat produced within the pump and by the UV lamp. The entire system, including reactor, vessel, tubing, etc., holds approximately $2 \mathrm{~L}$. The pump circulates water at a flow rate in excess of $10 \mathrm{~L} / \mathrm{min}$. This insures adequate mixing, enabling the system to be modeled as an ideal stirred-tank reactor. Figure 1 is a photograph and schematic of the complete reactor system.

\section{Lamps}

Tests at Sandia were performed with two different low-pressure mercury lamps. The near-UV lamp is a $15-\mathrm{W}$ fluorescent tube with peak emission at $366 \mathrm{~nm}$. This is used to activate the $\mathrm{TiO}_{2}$ photocatalyst, which absorbs below $390 \mathrm{~nm}$. The far-UV lamp is a 25-W low-pressure Hg quartz tube without a phosphor, and is designed for the production of ozone. This lamp has emissions at $185 \mathrm{~nm}, 254 \mathrm{~nm}$, and beyond. It is capable of activating $\mathrm{TiO}_{2}$, producing ozone, sterilizing, and driving a variety of photolytic reactions. Under the scope of this project, the near-UV lamp was used to produce data illustrating the capability of photocatalysis, while the far-UV lamp was used to examine the effectiveness of UV/ozone-type reactions. 

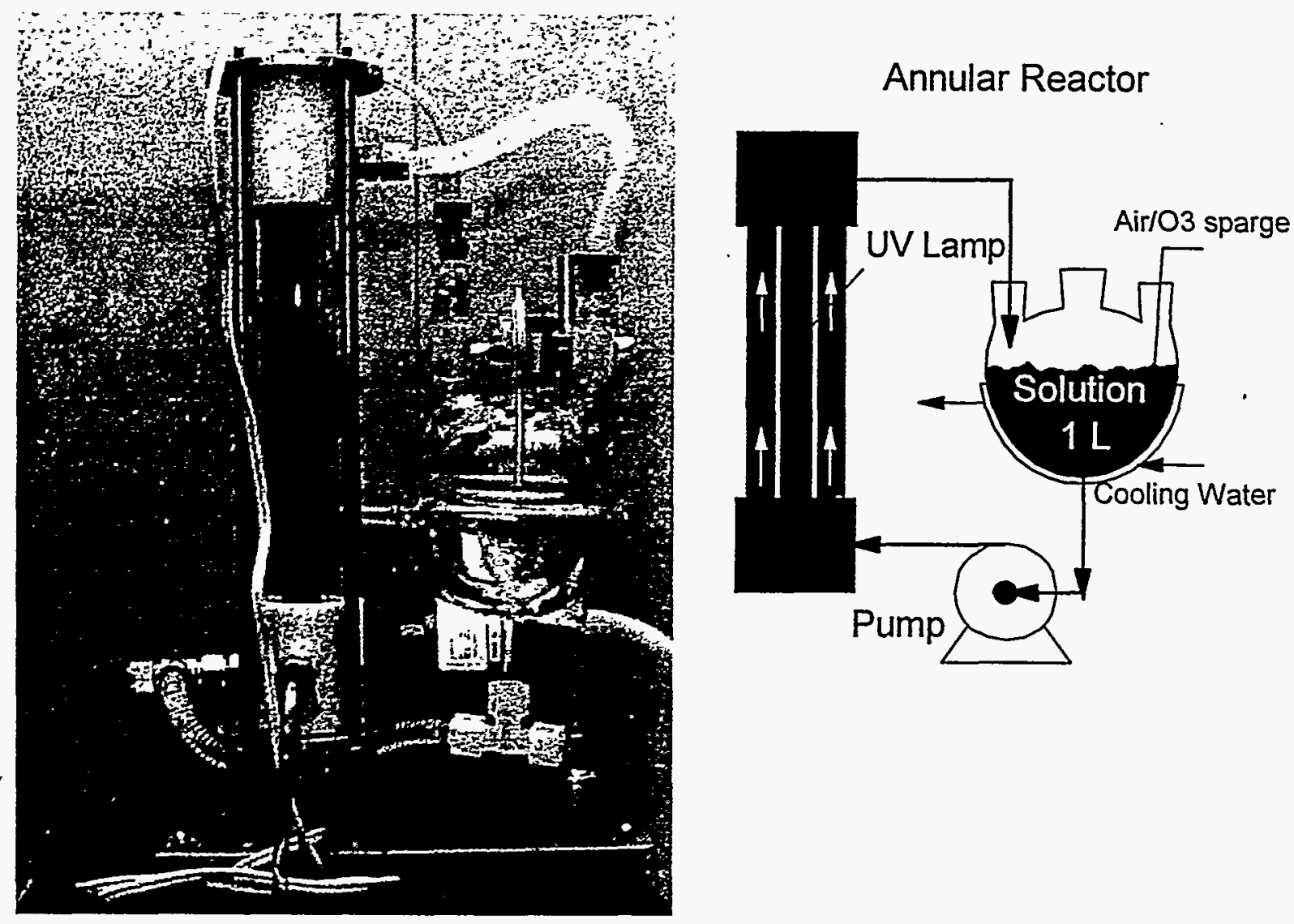

Figure 1 Photograph and flow schematic of the bench scale recirculating photoreactor. The black tube in the center of the reactor in the photograph is the near UV lamp.

At NREL, illumination in the recirculating batch photoreactor was provided by the $15-\mathrm{W}$ black-light bulb emiting at $366 \mathrm{~nm}$ as described above.

\section{Water Samples}

Two five-gallon samples were provided by Intel to Sandia; these samples were obtained from a water stream used to rinse wafers that had been treated in hydrofluoric acid (HF) and ethylene glycol. Each was said to contain ethylene glycol and trace HF, though a detailed composition analysis was not available. As received, the water exhibited a pH of 5.9 and TOC of $12 \pm 0.8$ $\mathrm{mg} / \mathrm{L}(\mathrm{ppm})$. This TOC value represents the mean of 20 analyses at the $99 \%$ confidence level.

Experiments were performed by placing $1200 \mathrm{~mL}$ of Intel water into the photoreactor, adding a catalyst if necessary, and beginning recirculation. After allowing several minutes for equilibration, a sample was withdrawn and the lamp was turned on $(t=0)$. Samples between 10 and $20 \dot{\mathrm{mL}}$ were then withdrawn later at specified times for analysis.

At NREL, catalyst tests were performed using $19 \mathrm{mg} / \mathrm{L}$ ethylene glycol in ultra pure water (Millipore). 


\section{Catalysts}

In experiments at Sandia that incorporated a catalyst, Degussa $\mathrm{P} 25 \mathrm{TiO}_{2}$ powder (P25), generally thought to be the best commercially available, was used. (P25 is a finely divided powder consisting of nominally $80 \%$ anatase and $20 \%$ rutile crystal phases, with a specific surface area of $50 \mathrm{~m}^{2} / \mathrm{g}$.) For most tests, the catalyst was used at a loading of $1 \mathrm{~g} / \mathrm{L}$.

At NREL, a total of nine catalysts were evaluated for ethylene glycol destruction. The composition of these catalysts is described in Table 1. Some of these catalysts were obtained commercially $\left(1,3,6,7\right.$, and 9), and the others were prepared in-house. The pure $\mathrm{TiO}_{2}$ catalysts consisted of stock $\mathrm{TiO}_{2}$ samples provided by the Degussa Corporation, Aldrich Chemicals, and Hombicat.

Table 1 Catalysts tested at NREL.

\begin{tabular}{|c|c|c|}
\hline Test \# & Catalyst & Oxidant \\
\hline 1 & Degussa $\mathrm{TiO}_{2}$ & None \\
\hline 2 & Au-Pt/TiO 2 (Aldrich) & None \\
\hline 3 & Degussa $\mathrm{SiO}_{2} / \mathrm{TiO}_{2}$ & None \\
\hline 4 & $\mathrm{Au} / \mathrm{TiO}_{2}$ (Aldrich) & None \\
\hline 5 & $\mathrm{Fe} / \mathrm{TiO}_{2}$ (Aldrich) & None \\
\hline 6 & Aldrich $\mathrm{TiO}_{2}$ & None \\
\hline 7 & Hombicat $\mathrm{TiO}_{2}$ & None \\
\hline 8 & $\mathrm{Fe} / \mathrm{TiO}_{2}$ & $100 \mathrm{ppm} \mathrm{H}_{2} \mathrm{O}_{2}$ \\
\hline 9 & Aldrich $\mathrm{TiO}_{2}$ & None \\
\hline
\end{tabular}

The $\mathrm{Au}$ and $\mathrm{Au}-\mathrm{Pt} \mathrm{TiO}_{2}$-based catalysts were conveniently prepared by photodeposting these metals directly onto the catalyst surface with a technique developed by Bard [4], in which glacial acetic acid serves as the sacrificial organic that is oxidized while the metal is reduced to the zero valance state at the $\mathrm{TiO}_{2}$ surface. These depostions were conducted under an inert atmosphere because if oxygen is present, it, rather than the metal, is preferencially reduced. Illumination was provided with a 1000-W Xenon arc lamp. The proprietary Fe-containing samples were prepared by an incipient wetness method. All the metallized catalysts were derived from Aldrich $\mathrm{TiO}_{2}$, which consists of $100 \%$ anatase. All catalysts were washed until the wash water reached $\mathrm{pH} 7$, dried at $100^{\circ} \mathrm{C}$, sieved through a 0.016 -inch screen, and sonicated in $10 \mathrm{ml}$ of ultra pure water prior to addition to the photoreactor to produce a weight loading of $1 \mathrm{~g} / \mathrm{L}$. Surface areas and particle sizes do not change for the metallized catalysts compared to untreated Aldrich $\mathrm{TiO}_{2}$.

\section{Oxidants}

For most experiments, the reaction solution was continuously sparged with air to provide dissolved oxygen as the oxidant. However, both $\mathrm{H}_{2} \mathrm{O}_{2}$ and sodium persulfate $\left(\mathrm{Na}_{2} \mathrm{~S}_{3} \mathrm{O}_{8}\right)$ have 
been shown by previous efforts to accelerate photocatalytic oxidation rates [5-7]. Consequently, these oxidants were employed in several experiments at varying initial concentrations. In most cases, the oxidant was added to the reactor at the beginning of the test. However, in two experiments a dilute solution of $\mathrm{H}_{2} \mathrm{O}_{2}$ was added continuously throughout the tests using a highperformance liquijd chromatography pump. This experiment was performed to determine if the slower, more uniform addition might result in more efficient utilization of the oxidant.

In one experiment, an air stream containing $150 \mathrm{ppm}$ ozone was sparged continuously into the bottom of the photoreactor at a rate of $0.6 \mathrm{~L} / \mathrm{min}$. The ozone was produced with an Enmet ozone generator (Model 04052-011).

\section{Samples}

Samples were removed at specific intervals prior to and during illumination and filtered using 0.2 micron Teflon filters before TOC or Gas Chromatography (GC) analyses.

\section{Analyses}

At Sandia, samples were analyzed with a Shimadzu TOC 5000 analyzer configured for high sensitivity, which provides meaningful TOC values as low as $100 \mu \mathrm{g} / \mathrm{L}(\mathrm{ppb})$. The system uses a Pt catalyst at $680^{\circ} \mathrm{C}$ to burn all the carbon in the sample. Resultant $\mathrm{CO}_{2}$ is monitored with an infrared detector. Each sample was injected into the TOC analyszer four times. The average TOC value satisfies a $4 \%$ limitation on $\sigma$.

At NREL, a GC direct-injection method was developed for analyzing ethylene glycol in the reacted solutions. The samples were centrifuged to remove any catalyst prior to direct injection on the GC column (capillary, $30 \mathrm{~m}$, Carbowax). Samples were run in triplicate and the concentration averaged for data analysis. (Triplicate analyses varied by up to $\pm 1 \%$ at the lowest concentrations.)

\section{Experimental Results}

A number of tests were conducted using near-UV and far-UV light sources alone and in combination with a variety of oxidants and photocatalysts:

\section{Near-UV Tests}

Base-case data were obtained in a series of initial experiments; these data are illustrated in Figure 2. Three identical photocatalysis experiments were conducted, and one experiment was run without any catalyst as a control. Data from these experiments were normalized by dividing each initial TOC value by the value recorded at time zero (before catalyst was added or illumination began). The average value from the three photocatalysis experiments constitutes the photocatalysis base case that is used for experimental comparisons. This series of tests demonstrates that: (1) without an added catalyst, destruction of TOC is insignificant; (2) with the addition of $\mathrm{TiO}_{2}$, total degradation of TOC can be achieved upon sufficient UV exposure; and 
(3) $10 \%$ of the sample's TOC is removed immediately by adsorption onto the catalyst, as indicated by a normalized initial TOC value of 0.9 . (To simplify graphic presentation of data, all subsequent graphs have TOC values normalized with the value achieved after adsorption has occurred.)

Figure 2 illustrates reproducibility, showing that the largest variations arise at the lowest concentrations (for TOC values below $1 \mathrm{mg} / \mathrm{L}$ ). These variations are assumed to have occurred as a result of reactor contaminants (e.g., soap), the minor adsorption of organics on surfaces within the system, and/or measurement error.

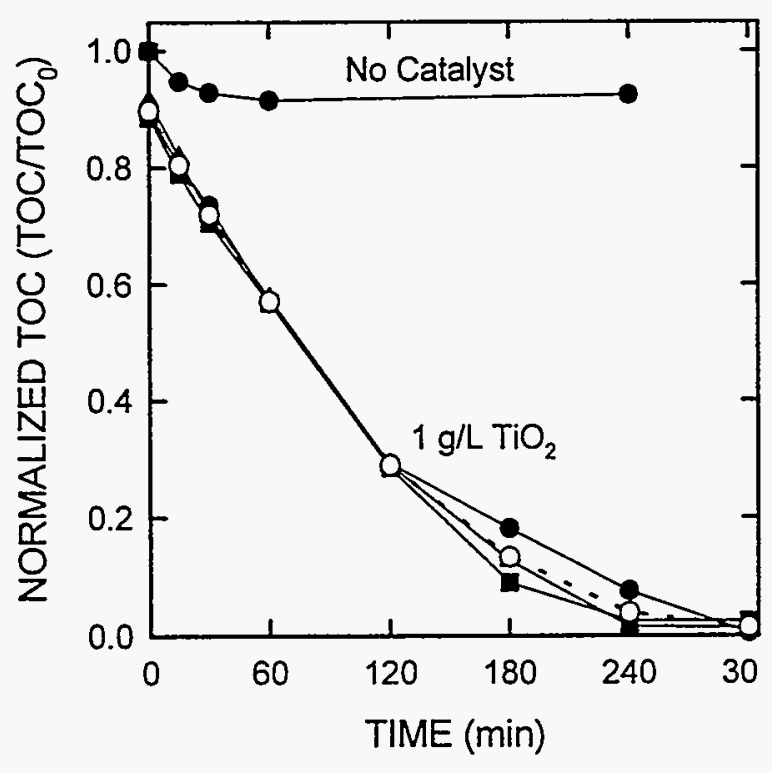

Figure 2. TOC destruction using the near-UV lamp. Open circles and dashed curve indicate the average of three replicates. This is the photocatalysis base case.

Figure 3 details the effects of the addition of $\mathrm{H}_{2} \mathrm{O}_{2}$ on photocatalysis kinetics. As shown, the initial addition of $10 \mathrm{mg} / \mathrm{L}$ and $100 \mathrm{mg} / \mathrm{L}$ of $\mathrm{H}_{2} \mathrm{O}_{2}$ did not significantly alter the TOC degradation rate, and the initial addition of $1000 \mathrm{mg} / \mathrm{L}$ proved detrimental. A slow, continuous addition of $5.1 \mathrm{mg} / \mathrm{min}$, however, considerably accelerated the destruction of TOC.

Previous research [6] has demonstrated that $\mathrm{Na}_{2} \mathrm{~S}_{3} \mathrm{O}_{8}$ (up to $0.1 \mathrm{M}$ ) can produce significant enhancements in the degradation rates of chlorophenol, dichlorodibenzodioxin, and atrazine. Results of its effect upon the photocatalytic treatment of Intel water are shown in Figure 4.

In this case, photocatalytic degradation is actually inhibited early on by the addition of $\mathrm{Na}_{2} \mathrm{~S}_{3} \mathrm{O}_{8}$. This induction period may be related to the accumulation of reactive species [9], competitive 


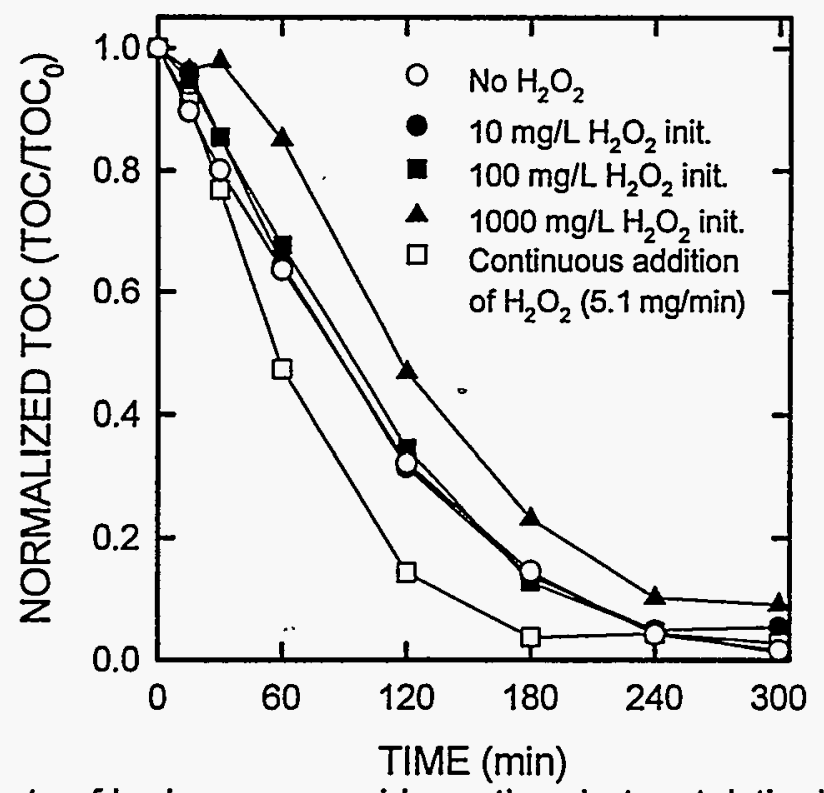

Figure 3. The effects of hydrogen peroxide on the photocatalytic degradation of TOC.

chemistry, light absorption, or something else. (There is some indication that persulfate interferes with TOC analysis.) More work would be required to understand this effect.

Because ozone is well known to mineralize organics in the presence and absence of UV light $[9,10]$, and because Intel uses ozone to inhibit the growth of algae in water tanks, in one experiment an air stream containing ozone was sparged continuously into the bottom of the photoreactor. No change was noted relative to the photocatalysis base case; hence, these data are not presented.

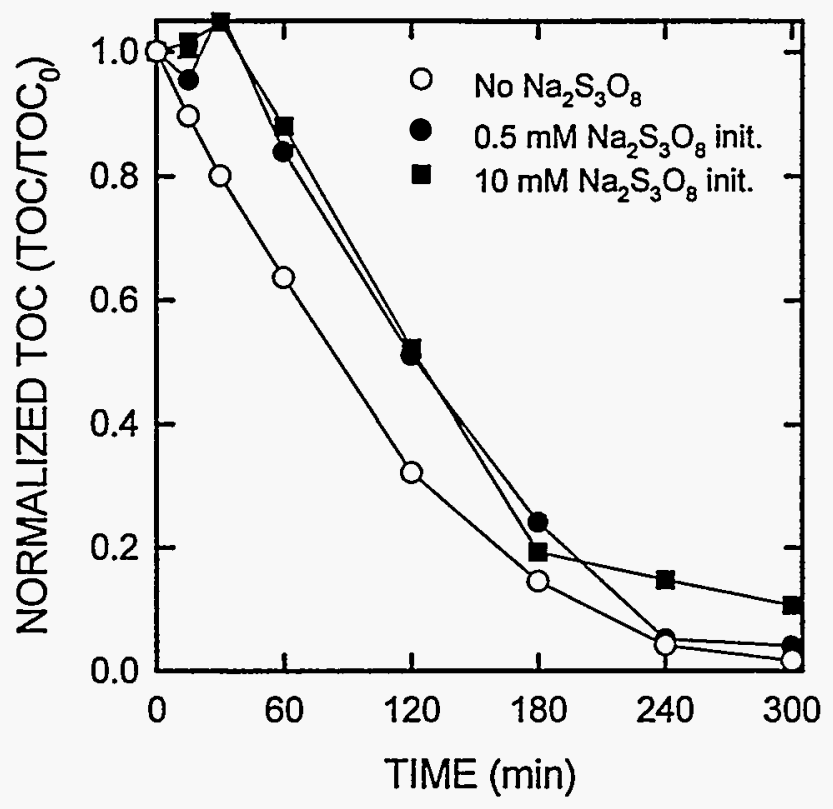

Figure 4. Sodium persulfate inhibits the photocatalytic degradation of TOC. 


\section{Far-UV Tests}

For the purposes of evaluating the performance of photocatalysis relative to available technology, data were also obtained from the more traditional process that generates hydroxyl radicals using far-UV light and ozone. Therefore, a series of experiments was conducted to determine if the more aggressive far-UV lamp would be advantageous as compared to near-UV photocatalysis. Results for the far-UV lamp operated under three different conditions are presented in comparison with the near-UV photocatalysis base case in Figure 5. When P25 is used at the standard loading of $1 \mathrm{~g} / \mathrm{L}$ with the far-UV lamp, only a slight acceleration in rate is observed. This is illustrative of the fact that benefits realized from the far-UV lamp are not related to photocatalysis. Rather, they arise from other photochemistry, such as the formation of ozone.

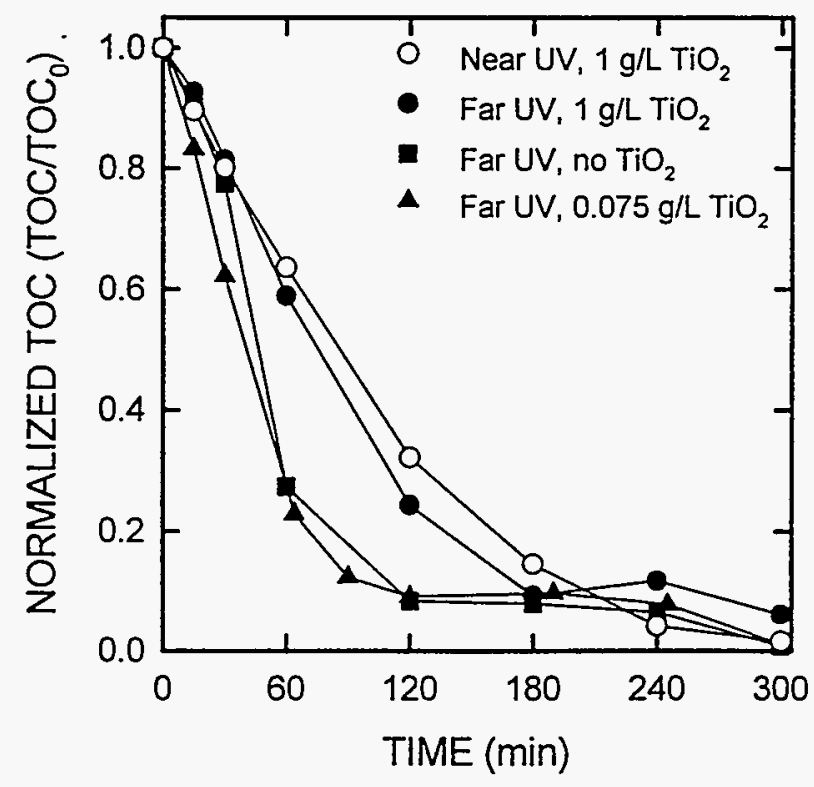

Figure 5. TOC destruction using the far-UV lamp; photocatalytic comparisons.

In contrast to the marked benefits exhibited with the addition of the photocatalyst with the near-UV source (Fig. 2), the far-UV degradation rate is substantially higher when no catalyst is used. It is likely that the far-UV lamp generates ozone in-situ, forming $\mathrm{H}_{2} \mathrm{O}_{2}$, which in turn absorbs some of the remaining UV light $(\lambda<250 \mathrm{~nm})$ to generate hydroxyl radicals [10]. These processes are inhibited when $\mathrm{TiO}_{2}$ is added because the catalyst absorbs all of the UV light, limiting the production of ozone. Under these specific conditions, the UV/ozone process is apparently more effective than the photocatalytic process for generating hydroxyl radicals.

A second test was conducted at a much lower catalyst concentration, $75 \mathrm{mg} / \mathrm{L}$, in an attempt to create a situation in which both high- and low-energy UV could penetrate the full crosssection of the reactor. Although it was determined that this lighter loading caused not more than $99 \%$ of the UV light at $356 \mathrm{~nm}$ to be absorbed, this configuration provided no benefit, as shown. 
An important result of this series of experiments is the determination that, in contrast to the near-UV photocatalytic tests, the far-UV source is unable to totally mineralize the organic material in the water sample, as evidenced by the flattening of the TOC traces at approximately $10 \%$ of their starting value. It is hypothesized that in the photocatalytic process, the $\mathrm{TiO}_{2}$ either adsorbs an unidentified refractory organic species, or adsorbs a refractory reaction by-product that forms in both near- and far-UV processes. A more detailed mass balance, including a carbon analysis on the used catalyst, is needed to verify the role of adsorption.

As detailed in Figure 6, this inability of the far-UV process to achieve complete TOC destruction can be easily overcome by the addition of $\mathrm{H}_{2} \mathrm{O}_{2}$. The initial addition of $19 \mathrm{mg} / \mathrm{L}$ was sufficient to result in substantial acceleration and total destruction of TOC within the acceptable margin of uncertainty. Unlike the near-UV photocatalytic process, no benefit is derived by adding $\mathrm{H}_{2} \mathrm{O}_{2}$ continuously.

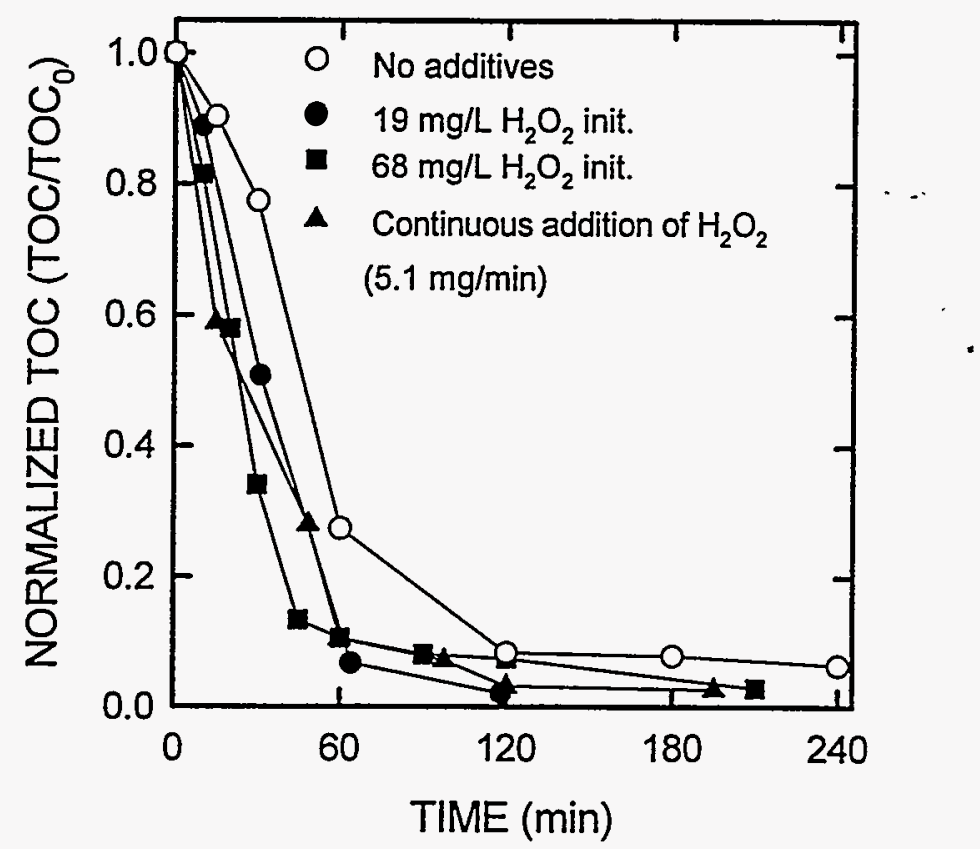

Figure 6. TOC destruction with the far-UV lamp and hydrogen peroxide. (Note that the time scale differs from that of Figures 2 through 5. .)

\section{Advanced Photocatalyst Tests (NREL)}

Figure 7 illustrates the four tests that were conducted to evaluate advanced photocatalysts 1 through 4 for degradation of ethylene glycol. As before, P25 is the base case, and illumination was achieved with a near-UV lamp.

Relative to the P25 base case, slightly enhanced performance was obtained with an experimental Degussa material, which contained an undisclosed amount of $\mathrm{SiO}_{2}$. The fastest 


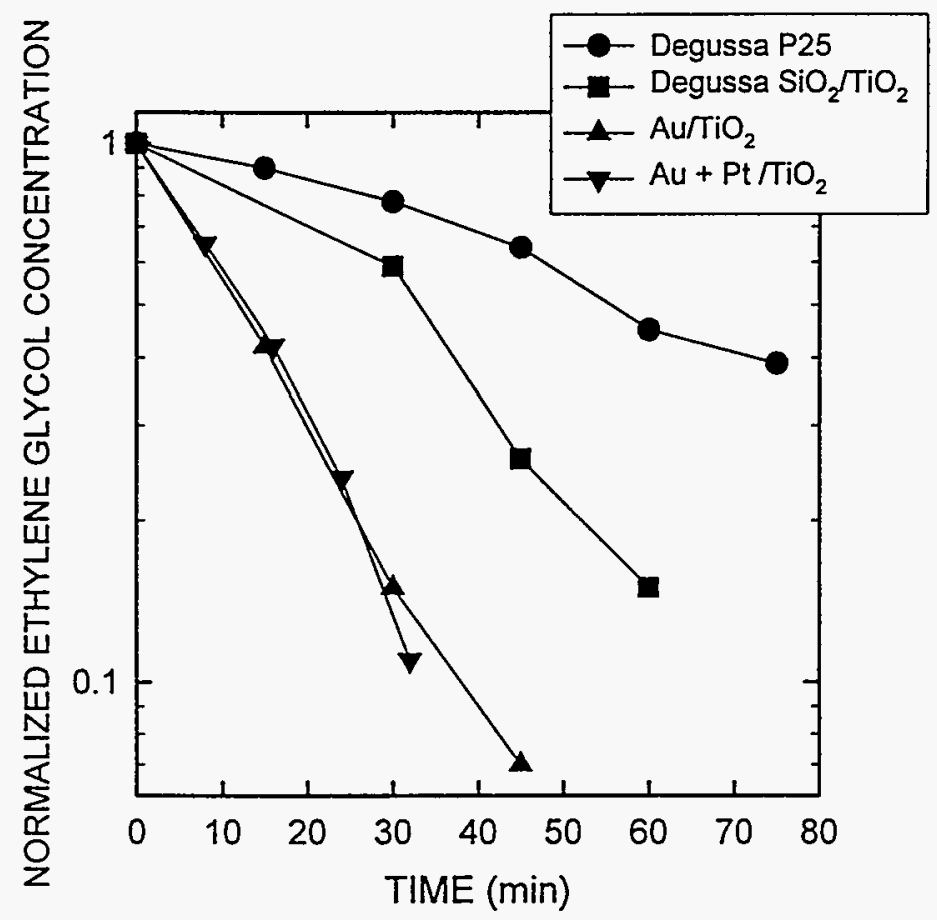

Figure 7. Photocatalyst activity for ethylene glycol destruction using four different catalysts

degradation of ethylene glycol was achieved with the metallized Aldrich samples; the Au$\mathrm{Pt} / \mathrm{TiO}_{2}(0.5 \%$ wt each of $\mathrm{Au}$ and $\mathrm{Pt})$ and the $\mathrm{Au} / \mathrm{TiO}_{2}(1 \%$ wt Au$)$. A comparison of the $\mathrm{Au}-\mathrm{Pt}$ catalyst with Sandia's near-UV/TiO ${ }_{2}$ base case for Intel water is presented in Figure 8.

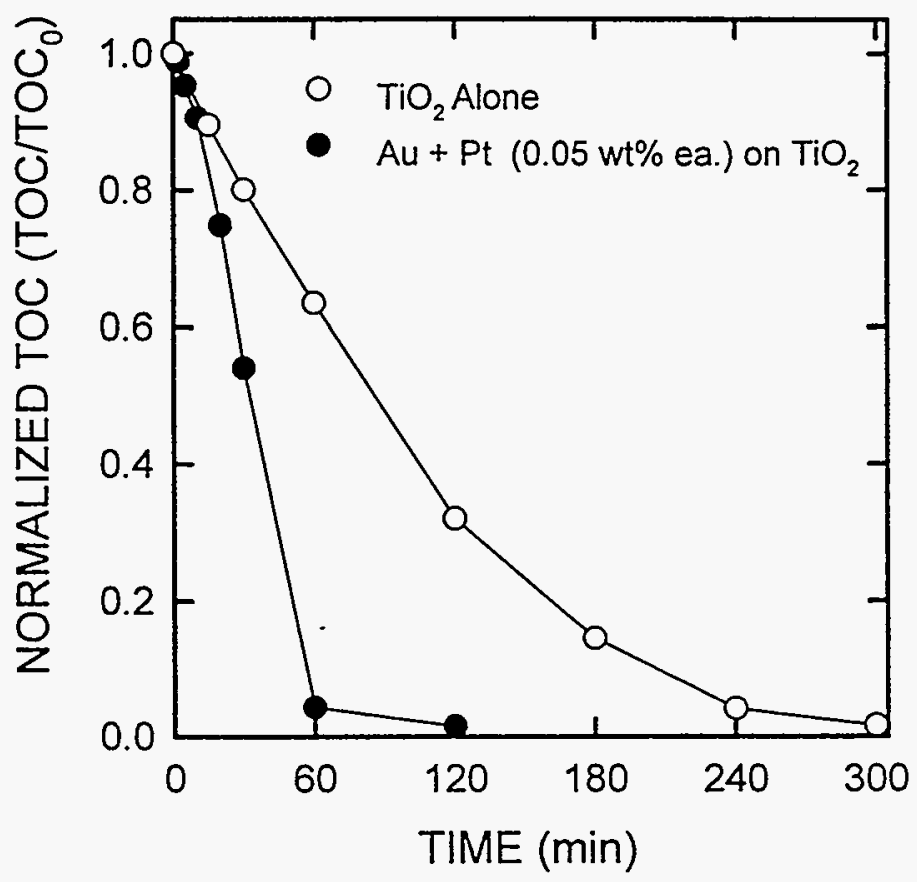

Figure 8. Au-Pt/ $\mathrm{TiO}_{2}$ (Aldrich) versus Degussa $\mathrm{P} 25 \mathrm{TiO}_{2}$ base case. 


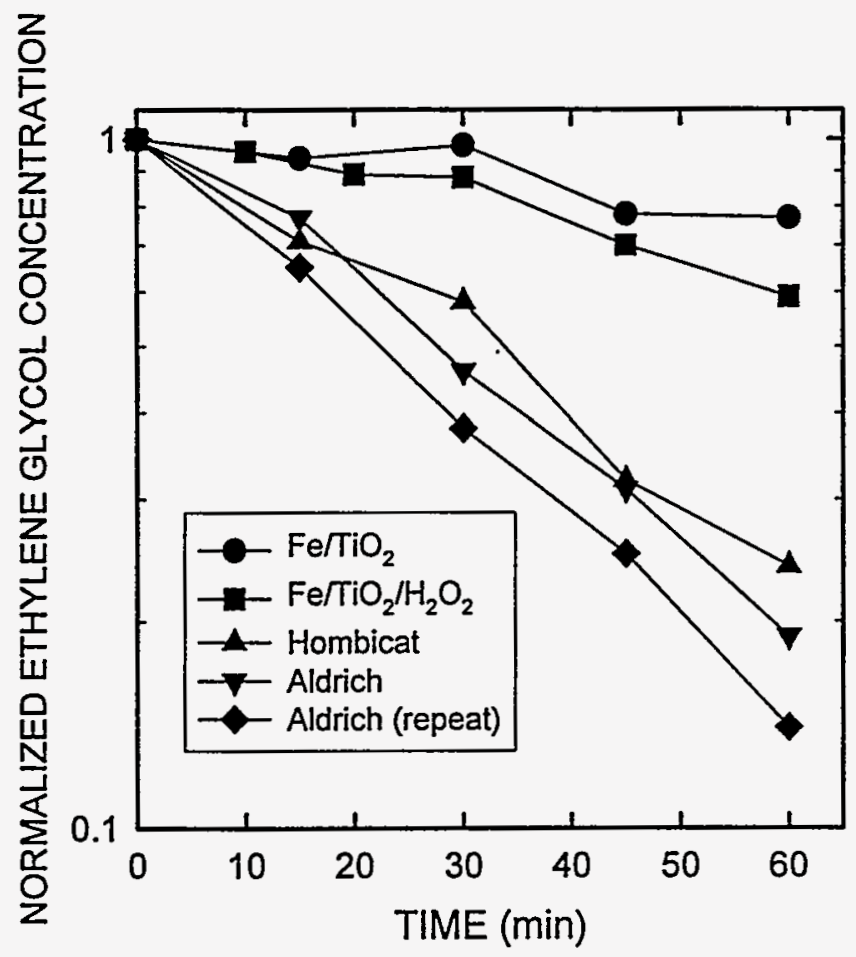

Figure 9. Photocatalyst activity for ethylene glycol destruction using four different catalysts.

Performance of the remaining five advanced catalysts is detailed in Figure 9, in which two $\mathrm{Fe} / \mathrm{TiO}_{2}$ samples and two brands of $\mathrm{TiO}_{2}$ (plus a replicate Aldrich $\mathrm{TiO}_{2}$ sample) were evaluated. Interestingly, although in previous work the Fe-containing catalyst has shown impressive performance for aqueous trichloroethylene oxidation, it exhibits the lowest activity of all the catalysts for glycol oxidation. Both Aldrich and Hombicat samples slightly outperform the Degussa material, although the replicate Aldrich experiments show a $25 \%$ variation in rates obtained under nearly identical conditions.

In all cases, heterogeneous catalyst performance was analyzed by calculating LangumuirHinshelwood-type rate constants $(k, K)$ for organic oxidation from concentration versus exposure time, according to the following equation:

$\mathrm{V} \frac{\mathrm{dC}}{\mathrm{dt}}=\frac{\mathrm{kKC}}{1+\mathrm{KC}}$

where

$$
\begin{aligned}
& t=\text { exposure time } \\
& C=\text { contaminant concentration } \\
& V=\text { reactor volume. }
\end{aligned}
$$


Table 2. Relative catalyst activities for aqueous ethylene glycol oxidation.

\begin{tabular}{|c|c|}
\hline Catalyst & Relative Activity \\
\hline Degussa $\mathrm{TiO}_{2}$ & 1.0 \\
\hline $0.5 \mathrm{wt} \% \mathrm{Au}-0.5 \mathrm{wt} \% \mathrm{Pt} / \mathrm{TiO}_{2}$ & 4.7 \\
\hline $1.0 \mathrm{wt} \% \mathrm{Au} / \mathrm{TiO}_{2}$ & 3.8 \\
\hline Degussa $\mathrm{SiO}_{2} / \mathrm{TiO}_{2}$ & 2.1 \\
\hline Aldrich $\mathrm{TiO}_{2}$ & 2.4 \\
\hline Aldrich $\mathrm{TiO}_{2}$ & 1.9 \\
\hline Hombicat $\mathrm{TiO}_{2}$ & 1.8 \\
\hline $\mathrm{Fe} / \mathrm{TiO}_{2}$ & 0.5 \\
\hline $\mathrm{Fe} / \mathrm{TiO}_{2} / \mathrm{H}_{2} \mathrm{O}_{2}$ & 0.6 \\
\hline
\end{tabular}

Concentration versus time data were fit to the integrated form of the equation to obtain values for the two rate parameters, which were then used to calculate reaction time to achieve $90 \%$ conversion for a standardized starting concentration. Reciprocals of these times were then ratioed against that for $\mathrm{P} 25$ to obtain the relative activities listed in Table 2.

\section{Discussion}

This project was primarily designed to generate data for determining the economic viability of photocatalysis for rendering Intel water recyclable. Data in Figures 2 through 6 and 8 were examined to ascertain the electric energy required to reduce the TOC in $1000 \mathrm{~L}$ of water to $1 / 10$ of its initial value, corresponding to a $90 \%$ reduction in TOC concentration from 12 to $1.2 \mathrm{ppm}$. Table 3 provides a summary of energy and chemical consumption for the seven most interesting experiments. Although a determination of energy required to reduce TOC by two orders of magnitude would be more useful, our detection limit of approximately 1 ppm prevents this. Nevertheless, a useful approach for extrapolating the results in Table 3 to $99 \%$ reduction in TOC concentration (valid for pseudo-first-order kinetics) is to simply multiply electricity needed to reach ten-fold reduction in TOC by a factor of two. Most of the data presented in this report follow pseudo-first-order kinetics well enough to make this approach valid.

Extrapolating information in a recent article on the capital cost of UV oxidation systems and reactors [8] suggests that a 10 gpm near-UV/Au-Pt-TiO ${ }_{2}$ system for reducing TOC by a factor of 10 would have capital costs between $\$ 50,000$ and $\$ 75,000$. Annual lamp replacement costs would reach $45 \%$ of the electricity costs [8]. 
Table 3 Summary of energy and oxidant requirements for the seven most interesting cases.

\begin{tabular}{|c|c|c|c|c|}
\hline Test & $\begin{array}{l}\text { Time to reach } \\
\text { ten-fold } \\
\text { reduction in } \\
\text { TOC (min) }\end{array}$ & $\begin{array}{l}\text { Electricity } \\
\text { required for } \\
\text { ten-fold } \\
\text { reduction in } \\
1000 \mathrm{~L} \\
(\mathrm{kWh} / 1000 \mathrm{~L})\end{array}$ & $\begin{array}{l}\mathrm{H}_{2} \mathrm{O}_{2} \text { required } \\
\text { for ten-fold } \\
\text { reduction in } \\
1000 \mathrm{~L} \\
(\mathrm{~g} / 1000 \mathrm{~L})\end{array}$ & Comments \\
\hline $\begin{array}{l}\text { Photocatalytic } \\
\text { with near-UV }\end{array}$ & 190 & 39.6 & 0 & $\begin{array}{l}\text { The photocatalysis } \\
\text { base case. Slow } \\
\text { but effective to } \\
\text { very low TOC } \\
\text { levels. }\end{array}$ \\
\hline $\begin{array}{l}\text { Photocatalytic } \\
\text { with continuous } \\
\text { addition of } \mathrm{H}_{2} \mathrm{O}_{2}\end{array}$ & 140 & 29.2 & 595 & $\begin{array}{l}\text { The best process } \\
\text { using the } \\
\text { traditional catalyst. } \\
\text { Achieves total } \\
\text { TOC destruction. }\end{array}$ \\
\hline $\begin{array}{l}\text { Photocatalytic } \\
\text { with near-UV }\end{array}$ & 240 & 50.0 & 1000 & $\begin{array}{l}\text { Worst case. } \\
\text { Excessive } \\
\text { peroxide inhibits } \\
\text { the reaction. }\end{array}$ \\
\hline $\begin{array}{l}\text { Photocatalytic } \\
\text { with } \mathrm{NREL} \mathrm{Pt} \\
\mathrm{Au} / \mathrm{TiO}_{2} \\
\text { photocatalyst }\end{array}$ & 51 & 10.6 & 0 & $\begin{array}{l}\text { The best } \\
\text { photocatalytic } \\
\text { process. Catalyst } \\
\text { may be expensive } \\
(\square \$ 80 / \mathrm{kg} \text { ). }\end{array}$ \\
\hline Far-UV only & 110 & 38.2 & 0 & $\begin{array}{l}\text { Fast but fails to } \\
\text { achieve total TOC } \\
\text { destruction. }\end{array}$ \\
\hline $\begin{array}{l}\text { Photocatalytic } \\
\text { with far-UV }\end{array}$ & 175 & 60.8 & 0 & $\begin{array}{l}\text { The photocatalyst } \\
\text { interferes. }\end{array}$ \\
\hline $\begin{array}{l}\text { Far UV with } 19 \\
\mathrm{mg} / \mathrm{L} \mathrm{H}_{2} \mathrm{O}_{2} \\
\text { initially }\end{array}$ & 60 & 20.8 & 19 & $\begin{array}{l}\text { The best far-UV } \\
\text { case. Total TOC } \\
\text { destruction. } \\
\text { Simple. }\end{array}$ \\
\hline
\end{tabular}

It would be possible to reduce energy consumption of the near-UV photocatalytic cases by employing a more efficient lamp. At present, efficiencies as high as $35 \%$ are obtainable from $15-W$ near-UV lamps, although the lamp used in the experiments at Sandia was tested using ferrioxalate actinometry at approximately $11 \%$ efficiency. At a presumed efficiency near $30 \%$, Sandia's far-UV results would not exhibit much improvement. However, based on manufacturer data sheets, new emerging flashlamps that broaden and shift light output to below $175 \mathrm{~nm}$ may be capable of achieving significantly improved TOC destruction [11]. 
In considering the encouraging results with the advanced photocatalysts, the following determinations must yet be made: (1) will the improved performance offset the added cost and time associated with handling, transportation, etc.; (2) could the new catalyst benefit from the addition of $\mathrm{H}_{2} \mathrm{O}_{2}$; and (3) if catalyst deactivation is an issue, how will it be addressed?

\section{Conclusion}

Both UV photocatalyst and UV/ozone processes are capable of treating the Intel water sample to below detection capabilities of TOC. The processes, however, are fairly energy intensive. It is presumed that a relatively small research effort could optimize UV/ozone, and possibly reduce operating costs by a factor of 2-5. Key variables for achieving this goal include the optimization of mass-transfer rates, light penetration, the UV source, and $\mathrm{H}_{2} \mathrm{O}_{2}$ deployment. Improvements in the catalytic process are possible with the use of better UV lamps and the development of higher-performance catalysts. Research must yet determine if these catalysts become fouled during use in actual waste water.

Based upon the outcomes of this project, further investigation into both the photocatalytic and UV/ozone processes is recommended, if energy consumption rates of 5-10 kWh/1000 L are deemed reasonable. 


\section{References}

1. G.R. Bamwenda, S. Tsubota, T. Kobayashi, and M. Haruta, J. Photochem. Photobiol. A.: Chem. vol.77, pp. 59-67, 1994.

2. P. Pichat, M.M. Mozzanega, J. Disdier, and J.M. Hermann, Nouv. Chim. vol 6(11), p. $559,1982$.

3. A. Sclafani, M.M. Mozzanega, and P. Pichat, J. Photochem. Photobiol. A:Chem. vol 59, pp. 181-189, 1991.

4. B. Krauetler and A.J. Bard, J. of Am. Chem. Soc. vol 100(13), pp. 4317, 1978.

5. J.E. Pacheco and L. Yellowhorse, Summary of Engineering-Scale Experiments for the Solar Detoxification of Water Project. SAND92-0385, Sandia National Laboratories, 1992.

6. E. Pelizzetti, V. Carlin, C. Minero, and M. Grätzel, New J. Chem. vol 15, pp. 351-359, 1991.

7. N.N. Lichtin, T.M. DiMauro-and R.C. Svrluga, Process for Degradation of Organic Materials in Aqueous and Organic Fluids to Produce Environmentally Compatible Products. U.S. Patent 4,861,484,1989.

8. R. Notarfonzo, and W. McPhee, Pollution Engineering. vol 26(10), pp. 74-76, 1994.

9. W.H. Glaze and J.W. Kang, Ind. Eng. Chem. Res. vol 28, pp. 1580-1587, 1989.

10. G.R. Peyton, Oxidative treatment methods for removal of organic compounds from drinking water supplies. Significance and treatment of VOCs in water supplies, N.M. Ram, R.F. Christman, and K.P. Cantor, eds., Lewis Publishers, pp. 313-362, 1991.

11. A. Wekhof, Env. Progress. vol 10, 1991. 
DISTRIBUTION

Intel Corporation

Attn: Scott Sibbett, MS SB9-30

4100 Sara Rd.

Rio Rancho, NM 87124

Intel Corporation

Attn: Rich Poliak

4100 Sara Rd.

Rio Rancho, NM 87124

National Renewable Energy Laboratory (6)

Attn: Dan Blake

Carol Lyons

Kim Magrini

Ed Wolfrum

Tom Williams

Mark Mehos

1617 Cole Blvd.

Golden, CO 80401

United States Department of Energy (2)

Waste Materials Management Divison EE-222

Attn: Frank Wilkins

Forrestal Building

1000 Independence Ave.

Washington, DC 20585

1127 Jim Chavez, 6215 (2)

1127 Library, 6215 (2)

0703 Mike Prairie, 6216 (25)

0703 Craig Tyner, 6216

0702 Dan Arvizu, 6200

1452 Phil Rodacy, 2652 (2)

0755 Art Verado, 6612

1077 Bob Blewer, 1305

9018 Central Technical Files, 8523-2

0899 Technical Library, 4414 (5)

0619 Technical Publications, 12615

0100 Document Processing, 7613-2 (2)

for DOE/OSTI 